\title{
Work-related musculoskeletal disorders among pesticide sprayers of tea plantations in South India
}

\author{
Ramesh $\mathbf{N}^{1}$, Kannan $\mathbf{R}^{2}$
}

'Department of Community Health, St John's Medical College, Bangalore, Karnataka, India, ${ }^{2}$ Department Department of Community Medicine, PK DAS Institute of Medical Sciences, Palakkad, Kerala, India,

\section{ABSTRACT}

Introduction: The kind of work performed and the environmental condition in which the work is performed contribute significantly to Work-related Musculoskeletal Disorder. The objective of this study was to assess the work-related musculoskeletal disorders among the pesticide sprayers in tea plantations.

Methods: A cross-sectional study was conducted among 290 chemical sprayers in selected tea plantations in South India from September to October 2018. Simple random sampling was done to select the sprayers for the study, written informed consent was taken and face-to-face interview was done with the sprayers. Sociodemographic factors and work profiles were noted. The Nordic Musculoskeletal Questionnaire was used for the evaluation of musculoskeletal complaints.

Results: Among the 290 sprayers in the study, all of them were males and the mean age of the participants was $45.6 \pm 8.5$ years. More than half of the study participants $152(52.4 \%)$ suffered from at least one musculoskeletal complaint and most of them $104(35.8 \%)$ had pain in more than one body part. Among them, more than one-third $101(34.8 \%)$ suffered from knee joint pain in the past twelve months. Shoulder problems (27.6\%), lower back (22.8\%) and upper back pains (19.3\%) were the other major work-related musculoskeletal disorders that the study participants faced in the past year. Knee pain (31.7\%), low backache $(20.7 \%)$ and shoulder pain $(24.1 \%)$ were the musculoskeletal problems that were related to their absence from work.

Conclusion: More than half of the sprayers had at least one musculoskeletal complaint. Most common issues included knee joint pain, shoulder pain and back pains.

Key words: Sprayers, Tea plantation, Work-related musculoskeletal illness

\section{INTRODUCTION}

A ccording to the Center for Disease Control and Prevention (CDC) report on workplace health promotion, Musculoskeletal disorders (MSD) are

\section{DOI: https://doi.org/10.3126/ijosh.v12i1.41034}

Conflicts of interest: None Supporting agencies: None

Date of submission: 11.09 .2021

Date of acceptance: 11.11 .2021

Date of publication: 01.01.2022

\section{Corresponding Author}

Dr. Radhika Kannan

Assistant Professor,

Department of Community Medicine,

PK DAS Institute of Medical Sciences,

Palakkad, Kerala, India

Phone No.: +919400578590

Email: pkdimsrad@gmail.com

ORCID: https://orcid.org/0000-0002-8058-5840 injuries or disorders of the muscles, nerves, tendons, joints, cartilage, and spinal discs. The kind of work performed and the environmental condition in which the work is performed contribute significantly to Workrelated Musculoskeletal Disorder (WMSD). MSD does not include disorders caused by slips or falls. It includes sprains, strains, tears, back pain, carpal tunnel syndrome and hernia. ${ }^{1,2,3}$

Tea is one of the most popular beverages all over the world. India is the second-largest producer of tea in the world next to China, with a production of 1267 million kilograms of tea annually. Indian tea is one of the most popular beverages globally and South India contributes to almost one-third of the total production. ${ }^{4}$ India is also

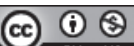

This journal is licensed under a Creative Commons AttributionNon Commercial 4.0 International License. 
the world's largest consumer of tea with three- fourth of its total production consumed locally. The tea exports have reached 837 million dollars in 2017-2018 and contribute to five percent of the national income in agriculture. $^{5}$

The plantation industry is composed of a complex chain of workers whose functions often overlap. The main workforce in the plantation industry includes people involved in various activities like spraying, weeding, tree cutting, pruning and plucking. ${ }^{6}$ Sprayers working in tea plantations are primarily engaged in pesticide spraying for the tea plants. They will be involved in this activity at regular intervals throughout the year.

The plantation workforce is among the most underprivileged people in the organized sector - low wages, poor working and living conditions, work in remote and isolated areas, and are mostly illiterate. There are migrant workers with no awareness or information about their rights. ${ }^{7,8}$ Hence, there are chances of increased incidence of musculoskeletal disorders among them. ${ }^{9}$

While there are a few studies done among plantation workers, very few are done to date on the sprayers of tea plantations; hence there is scope to explore this area of work further. The current study was undertaken using reliable screening and diagnostic tools to assess the work-related musculoskeletal injuries among the pesticide sprayers in selected tea plantations in South India.

\section{METHODS}

A cross-sectional study was conducted among 290 chemical sprayers in selected tea plantations in South India after approval from Institutional Ethics Committee of St John's Medical College, Bangalore (Approval number:272/2017) and permission from the plantations. Sample size was calculated using the formula:

$\mathrm{n}=\left\{\mathrm{z}^{2}(\mathrm{pq}) / \mathrm{d}^{2}\right\}=354$

$z=$ relative deviate (at $95 \%$ confidence interval) i.e. 1.96

$\mathrm{p}=$ prevalence taken as $36 \%$ (study by $\mathrm{M}$ Fareed et al) ${ }^{10}$

$q=100-p$

$d=$ precision (taken as $5 \%$ )

Finite population correction $=(\sqrt{ } \mathrm{N}-\mathrm{n} / \mathrm{N}-1){ }^{*}$ Calculated sample size

$\mathrm{N}=$ Known sample population (here the total number of sprayers was 750 ) $\mathrm{n}=$ calculated sample size

Finite population correction $=0.721$

Corrected sample size $=0.721 * 354=255$

However, in this study, we were able to interview all the sprayers who attended the annual health appraisals on the days of data collection. Totally 290 sprayers were included in our study.

Written informed consent was taken and the sprayers were interviewed either in the muster or at the Estate Hospital after their working hours.

A mutually agreed date was fixed for the health appraisals of the sprayers and the investigators visited the estates on these agreed dates to conduct the interviews with the sprayers. With the help of the Medical Officer, Estate Hospital and the managers of the consenting estates, a list of all sprayers working in their estates was made. From the total list, simple random sampling was done to select the sprayers for the study. A structured interview schedule was administered by face-to-face interviews with the sprayers.

Sociodemographic details were included. Modified BG Prasad classification for 2019 was used to categorize the subjects into five socioeconomic classes taking Consumer Price Index as Rs. 307.

\begin{tabular}{cc}
\hline $\begin{array}{c}\text { Modified BG Prasad } \\
\text { Social Class }\end{array}$ & $\begin{array}{c}\text { Monthly Per capita } \\
\text { income }\end{array}$ \\
\hline I (Upper) & 7008 and above \\
II (Upper Middle) & $3504-7007$ \\
III (Middle) & $2102-3503$ \\
IV (Lower Middle) & $1051-2101$ \\
V (Lower & Less than 1050 \\
\hline
\end{tabular}

Medical history included the current illness (past 2 weeks), chronic illness, regular medications, past medical or surgical history, consumption of alcohol and tobacco. Type of work and duration, hours of pesticide exposure, methods used in spraying, other activities done were included in the work-related history.

The Nordic musculoskeletal questionnaire is an internationally accepted tool designed to standardize studies on the evaluation of musculoskeletal complaints. It is a reliable and valid tool used in different occupational settings to identify the different musculoskeletal problems among the workers. ${ }^{11,12}$

The questionnaire had a picture showing the anatomy of the human body including nine body parts - neck, 
shoulders, upper back, lower back, elbow, wrist/hands, thighs, knees, ankle/feet. The study participants were asked if they had trouble in any of the shaded areas one by one during the preceding 12 months and 7 days. If it prevents them from going to work was also enquired. Each participant could give a response of "yes" or "no" to each of the nine parts and one confirmatory answer was allowed. ${ }^{13,14,15,16}$

Data were entered into Microsoft Excel and analyzed using IBM SPSS version 21.

\section{RESULTS}

\section{Sociodemographic profile of the study population}

Among the 290 sprayers in the study, almost half of them $(47.6 \%)$ were in the age group of 41 to 50 years. All of them were males and the mean age of the participants was $45.6 \pm 8.5$ years. In this study, $45.5 \%$ had completed high school and $29.7 \%$ had middle school education. The majority of them were married and $18 \%$ of them were migrants coming mostly from the Northeastern parts of India. Half of the study population belonged to class three of modified BG Prasad socioeconomic classification. In this study, modified BG Prasad's scale for socio-economic status classification was used taking Consumer Price Index= 307.

It was seen that more than half of the study population had worked for over 20 years as sprayers on the plantation. The most common devices used for spraying were high volume sprayer and the knapsack sprayer.

The mean duration of work was $22.74 \pm 7.12$ years. Nearly half of the study population $129(44.5 \%)$ had work experience as sprayers of 21 to 30 years in the tea estates. Spraying activity was carried-out for fivesix hours a day for six days in a week for almost eight to ten months in a year.

Apart from spraying, the other activities done by the study population were plucking, weeding and pruning. The study showed that $10.6 \%$ had availed sick leaves in the past three months which was confirmed from their records.

More than half of the study participants $152(52.4 \%)$ suffered from at least one musculoskeletal problem and most of them $104(35.8 \%)$ had pain in more than one body part.
Among the 290 study participants, more than onethird $(34.8 \%)$ suffered from knee joint pain in the past 12 months. Shoulder problems (27.6\%), lower back $(22.8 \%)$ and upper back pains (19.3\%) were the other major work-related musculoskeletal disorders that the study participants faced in the past year.

About one-third (31.7\%) of the sprayers were absent from the work in the past year due to knee-related problems. Low backache $(20.7 \%)$ and shoulder pains $(24.1 \%)$ were the other musculoskeletal problems that were related to their absence from work.

Table 1: Socio-demography of the study population $(n=290)$

\begin{tabular}{lc}
\hline Age group (Years) & Number of respondents (\%) \\
\hline$<21$ & $4(1.4)$ \\
$21-30$ & $17(5.9)$ \\
$31-40$ & $50(17.2)$ \\
$41-50$ & $138(47.6)$ \\
$51-60$ & $79(27.2)$ \\
$\geq 61$ & $2(0.7)$ \\
Education & \\
\hline Illiterate & $19(6.6)$ \\
\hline Primary school & $38(13.1)$ \\
\hline Middle school & $86(29.7)$ \\
\hline High school & $132(45.5)$ \\
PUC & $14(4.8)$ \\
\hline Degree & $1(0.3)$ \\
Marital status & \\
Married & $282(97.2)$ \\
Unmarried & $8(2.8)$ \\
Socioeconomic class & \\
(Modified BG Prasad) & \\
Upper & $4(1.4)$ \\
\hline Upper middle & $73(25.2)$ \\
\hline Middle & $141(48.6)$ \\
Lower middle & $70(24.1)$ \\
Lower & $2(0.7)$ \\
Total & $\mathbf{2 9 0 ( 1 0 0 )}$ \\
\hline
\end{tabular}

Table 2: Methods used for spraying $(n=290)$

\begin{tabular}{lc}
\hline Methods & Frequency (\%) \\
\hline High Volume Sprayer & $113(39)$ \\
$\begin{array}{l}\text { Knapsack (manually operated) } \\
\text { sprayers }\end{array}$ & $106(36.6)$ \\
$\begin{array}{l}\text { Power machine - Lu-shyong } \\
\text { (operated by petrol) }\end{array}$ & $71(24.5)$ \\
Total & $\mathbf{2 9 0}$ \\
\hline
\end{tabular}


Ramesh $\mathrm{N}$ et al.

Table 3: Duration of work done as sprayer $(n=290)$

\begin{tabular}{cc}
\hline Duration (Years) & Frequency (\%) \\
\hline $0-10$ & $46(15.9)$ \\
$11-20$ & $69(23.8)$ \\
$21-30$ & $129(44.5)$ \\
$\geq 31$ & $46(15.9)$ \\
Total & $\mathbf{2 9 0}$ \\
\hline
\end{tabular}

Table 4: Details of musculoskeletal pain prevented study participants from going to work

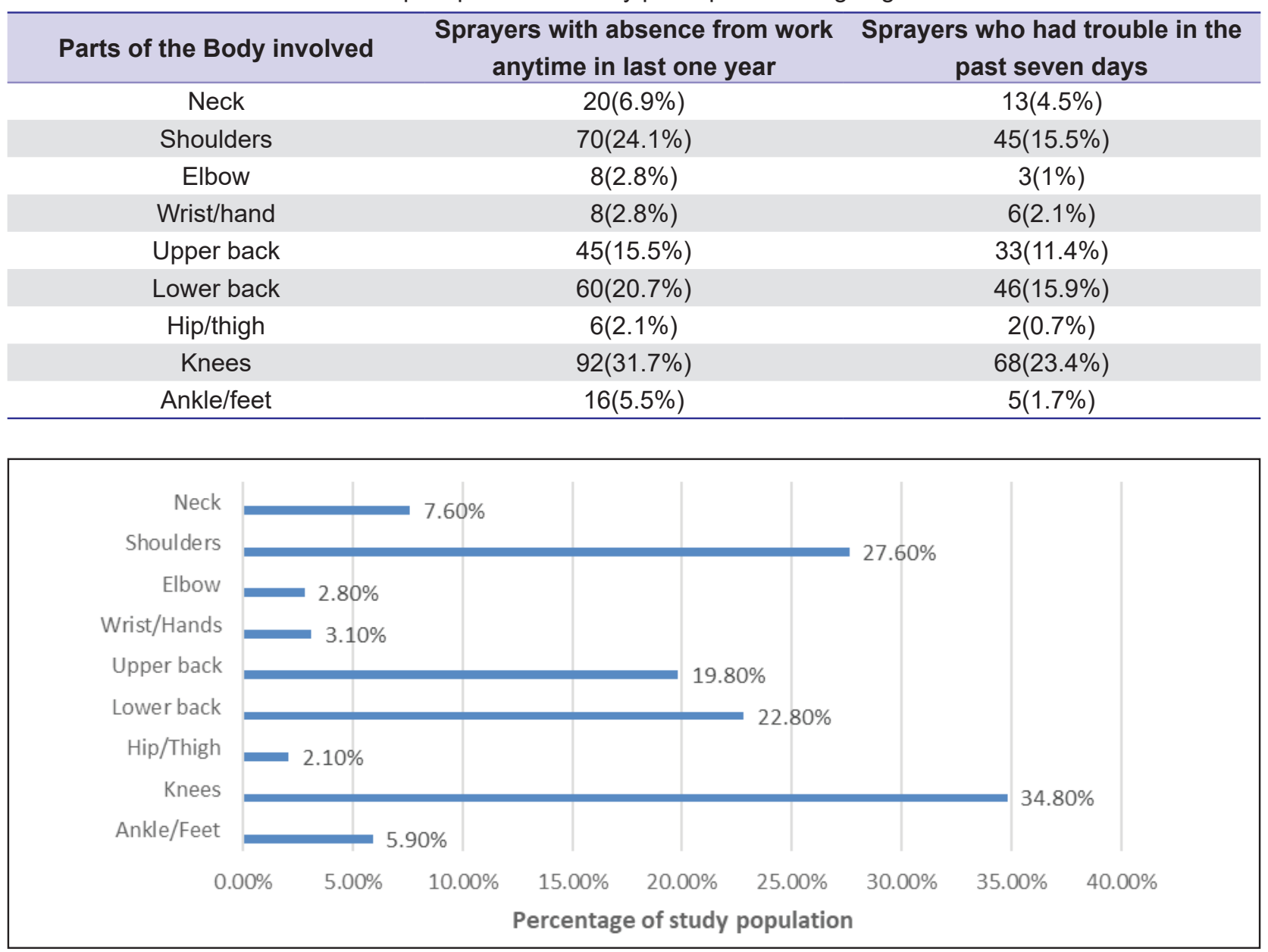

Figure 1: Distribution of musculoskeletal pain in past 1 year among the study population

\section{DISCUSSION}

The finding that all the sprayers in this study were males was obviously due to the selection of only males for the activity of spraying, considering it strenuous and exhaustive. Other reasons could be due to social issues, tradition and the use of heavy machinery which might be difficult for the females. Similarities were seen in other studies conducted in Lucknow among pesticide sprayers which reported that only male sprayers were included in the study which could be obviously due to the employment of predominantly males for this activity in those areas also. ${ }^{16}$ But the employment in tea plantation as such do not have any gender preferences and females are usually employed more and involved in activities like plucking, weeding, transportation, pruning and nursing young plants. ${ }^{17}$

More than half of the study participants had at least one musculoskeletal problem. More than one-third of them suffered from knee joint pain in the past twelve months. Shoulder problems $(27.6 \%)$, lower back $(22.8 \%)$ and upper back pains (19.3\%) were the other major work-related musculoskeletal disorders that the study participants faced in the past year. The most common musculoskeletal problems that prevented 
them from going to work in the past seven days were knee pain and low-back pain.

These musculoskeletal problems were attributed to the weight of the equipment carried at the back and the climbing of steep slopes for spraying. Some of them even reported that the machines had large pipes that had to be pulled for long distances causing aches in the upper and lower limbs.

In a study done to assess the prevalence of musculoskeletal disorders and occupational health problems among groundnut farmers of West Bengal, it was shown that lower back (99\%), knee (92\%) and ankle $(66 \%)$ problems were most common. ${ }^{6}$ The subjects in this study also had complained of pain in similar sites, but the proportion of sprayers with the complaints were much lesser.

Another study done among the tea leaf pluckers in a tea plantation in Tamil Nadu showed the prevalence of musculoskeletal pain in the last one year and last seven days as $83.6 \%$ and $78.5 \%$ respectively. The most common site of pain in the last year was the shoulder (59\%) and the last seven days was the lower back $(52.8 \%){ }^{8}$ The reason for shoulder pain is more prominent in this category as compared to our study group could be the plucking activity they do and the tea leaves being carried by them.

\section{REFERENCES}

1. Canadian Centre for Occupational Health and Safety. Work-related Musculoskeletal Disorders (WMSDs) : OSH Answers [Internet]. Web page. 2018 [cited 2019 Sep 19]: 1. Available from: https://www.ccohs.ca/ oshanswers/diseases/rmirsi.html

2. Thetkathuek A, Meepradit P, Sangiamsak T. A Crosssectional Study of Musculoskeletal Symptoms and Risk Factors in Cambodian Fruit Farm Workers in Eastern Region, Thailand. Saf Health Work. 2018 Jun 1; 9(2):192-202.

3. Das B, Ghosh T, Gangopadhyay S. Prevalence of musculoskeletal disorders and occupational health problems among groundnut farmers of West Bengal, India. J Hum Ergol (Tokyo) [Internet]. 2013 [cited 2019 Sep 19];42(1-2):1-12. Available from: https:// www.researchgate.net/publication/272081863

4. Moitra S. Respiratory Morbidity among Indian Tea Industry Workers. Indian J Occup Environ Med. 2016;7(3):148. Available from: https://www.ncbi.nlm. nih.gov/pmc/articles/PMC6818078/
A similar study among agricultural workers in Korea showed that $97.2 \%$ of workers had pain in at least one site- shoulder, knee and lower back which were the most common areas of work-related musculoskeletal pain. ${ }^{18}$ These were similar to the findings in our study.

\section{CONCLUSION}

The study found that work-related musculoskeletal disorders were common among the tea plantation sprayers and many of them had involvement of more than one body part. Knee pain and lower backache were the most common issues identified. These issues had also prevented them from going to work on multiple occasions that can indirectly affect the productivity in this sector.

Ergonomics are to be followed during the spraying activity. It is important to ensure that the machines carried by the sprayers fit them correctly and the right postures are adopted by them while spraying. Training and health education sessions for the same are to be arranged for the employees. This can help to decrease the burden of musculoskeletal disorders among sprayers.

\section{ACKNOWLEDGEMENTS}

We thank all the plantation managers and the staff of the different estates for their cooperation in conducting this study.

5. Indian Tea: Industry, Market \&amp; Export Data From The Tea Board of India I IBEF [Internet]. [cited 2019 Mar 17]. Available from: https://www.ibef.org/exports/ indian-tea-industry.aspx

6. Tea | History of Tea Drinking In India [Internet]. [cited 2019 Mar 17]. Available from: http://www.tea.in/ history

7. Jain R, Meena ML, Dangayach GS, Bhardwaj AK. Risk factors for musculoskeletal disorders in manual harvesting farmers of Rajasthan. Ind Health. 2018;56(3):241-8.

8. Vasanth $D$, Ramesh N, Fathima FN, Fernandez $\mathrm{R}$, Jennifer S, Joseph B. Prevalence, pattern, and factors associated with work-related musculoskeletal disorders among pluckers in a tea plantation in Tamil Nadu, India. Indian J Occup Environ Med. 2015 Sep 1;19(3):167-70.

9. Naveen R, Swaroop N, Agrawal S, Tirkey AK. Profile of occupational accidents reporting to a rural Plantation Hospital: A record review. Int J Occup Saf Heal. 2014 Feb 10;3(2):18-20. 
10. Fareed M, Pathak MK, Bihari V, Kamal R, Srivastava AK. Adverse Respiratory Health and Hematological Alterations among Agricultural Workers Occupationally Exposed to Organophosphate Pesticides : A Cross- Sectional Study in North India. 2013;8(7):1-10.

11. Sirajudeen MS, Alaidarous M, Waly M, Alqahtani M. Work-related musculoskeletal disorders among faculty members of college of Applied Medical Sciences, Majmaah University, Saudi Arabia: A cross-sectional study. Int J Health Sci (Qassim) [Internet]. 2018;12(4):18-25.Availablefrom: http:// www.ncbi.nlm.nih.gov/pubmed/30022899

12. Kuorinka I, Jonsson B, Kilbom A, Vinterberg $H$, Biering-Sørensen $F$, Andersson $G$, et al. Standardised Nordic questionnaires for the analysis of musculoskeletal symptoms. Appl Ergon [Internet]. 1987;18(3):233-7. Available from: http://www.ncbi. nlm.nih.gov/pubmed/15676628

13. Hendi OM, Abdulaziz AA, Althaqafi AM, Hindi AM, Khan SA, Atalla AA. Prevalence of Musculoskeletal Disorders and its Correlation to Physical Activity Among Health Specialty Students. Int J Prev Med [Internet]. 2019 [cited 2019 Jun 22];10:48. Available from: http://www.ncbi.nlm.nih.gov/pubmed/31143422

14. Yazdi M, Zeverdegani SK, MollaAghaBabaee AH. Association of derived patterns of musculoskeletal disorders with psychological problems: a latent class analysis. Environ Health Prev Med [Internet]. 2019 [cited 2019 Jun 22];24. Available from: https://www.ncbi.nlm.nih.gov/pmc/articles/ PMC6521474/

15. Mekonnen TH, Abere G, Olkeba SW. Risk Factors Associated with Upper Extremity Musculoskeletal Disorders among Barbers in Gondar Town, Northwest Ethiopia, 2018: A Cross-Sectional Study. Pain Res Manag [Internet]. 2019 [cited 2019 Jun 22]; 2019:6984719. Available from: http://www.ncbi.nlm. nih.gov/pubmed/31073353

16. Santoshi JA, Jain S, Popalwar HJ, Pakhare AP. Musculoskeletal disorders and associated risk factors in coaching students: A cross-sectional study. J Fam Med Prim care [Internet]. 2019 Mar [cited 2019 Jun 22];8(3):929-33. Available from: http://www.ncbi.nlm. nih.gov/pubmed/31041227

17. Ahmmed F, Hossain MI. A Study Report on Working Conditions of Tea Plantation Workers in Bangladesh. 2016;90.

18. Kee D, Haslam R. Prevalence of work-related musculoskeletal disorders in agriculture workers in Korea and preventative interventions. 2019;64(4):763-75. Available from: https://pubmed. ncbi.nlm.nih.gov/31815716/ 